Boise State University

ScholarWorks

English Faculty Publications and Presentations

Department of English

$10-1-2017$

\title{
Writing and Women's Retention in Engineering
}

Jennifer C. Mallette

Boise State University

Mallette, J.C., Writing and Women's Retention in Engineering, Journal of Business and Technical Communication, 31(4), pp. 417-442. Copyright ( 2017 , SAGE Publications. Reprinted by permission of SAGE Publications. doi: $10.1177 / 1050651917713253$ 
This is an author-produced, peer-reviewed version of this article. The final, definitive version of this document can be found online at Journal of Business and Technical Communication, published by SAGE. Copyright restrictions may apply. doi: 10.1177/1050651917713253

\title{
Writing and Women's Retention in Engineering
}

\author{
Jennifer C. Mallette \\ English Department \\ Boise State University \\ Boise, ID \\ jennifermallette@boisestate.edu
}

\begin{abstract}
Engineering disciplines have focused on recruiting and retaining women, assessing factors that contribute to decisions to enter or exit the field at every level. While many studies have examined writing in engineering disciplines, few have looked at writing's role in women's decisions to remain in or leave engineering. Using a case study of a professional civil engineer, Katy, this study examines the role that writing played in her dissatisfaction with engineering and her ultimate decision to leave the field. The author analyzes two genres of writing, meeting minutes and a preliminary engineering report, to explore how Katy's writing practices often ran counter to her coworkers' or supervisors' approaches. While a single case study makes generalization impossible, this work opens the door to future research that accounts for writing in recruiting and retaining women.
\end{abstract}

Keywords: engineering communication, feminism, efficiency, retention, gender

As a minority in engineering, women struggle to assert their competence and their commitment to their work, especially in relation to the ideology of efficiency. Writing production is one location where this struggle is revealed, and studies of engineering discourse have focused on the ways texts operate within organizations to accomplish action (Leydens, 2008; Winsor, 1996; 2003). Historically, women have been linked with writing because writing was deemed an acceptable way for them to contribute in engineering and science settings even if they were denied access elsewhere in these fields (Malone, 2010; 2011; Rossiter, 1995). Because of the power of discourse in engineering, writing would seem to offer an avenue for women to demonstrate their ability and be accepted by the profession, yet the picture is more complicated. For Katy, a civil engineer, writing was a way to demonstrate her professional competence and her dedication to the principle of efficiency. However, her written work also revealed the forces-both gendered and intellectual—-that would in part precipitate her exit from the profession.

A highly curious individual, Katy sees herself as an engaged citizen striving for social justice. As an undergraduate, Katy chose civil engineering as her major after browsing the course catalog until she found a field of study that sounded not only interesting but also challenging. She also earned a master's degree in civil engineering, specializing in environmental engineering, and beginning a career as a consulting engineer for an environmental engineering firm. While research demonstrates that some women are attracted to engineering and other science, technology, engineering, and mathematics (STEM) fields if they see an opportunity to accomplish social good (Metz, 2007), others women have alternate reasons that draw them to affect their decisions to leave these fields. Although Katy recognized that engineering gave her chance to contribute to society, her initial impulse was to pursue a field that was intellectually stimulating. Despite Katy excelling in her education and as a consulting engineer, after 10 years with her firm, she could no longer tolerate the working environment and began actively transitioning out of the field to run her own business.

Unfortunately, Katy's story is familiar to those who examine the persistence of women in the male-dominated field that is engineering. Researchers examining the "leaky pipeline" have observed that women tend to leave engineering and other STEM fields at higher rates than men do, for a variety of reasons (Burke \& Mattis, 2007; Stewart, Malley, \& LaVaque-Manty, 2007). These reasons include a hostile working environment, lack of female mentors and role models, higher expectations for their performance, little recognition for their achievements, and workplace policies that are unfriendly to women, especially mothers (Burke, 2007; Dean \& Fleckenstein, 2007; Liang and Bilimoria, 2007; Moss-Racusin, Dovido, Brescoll, Graham, \& Handelsman, 2012; Yates, 2001). In addition, women who show aptitude for mathematics are often diverted from pursuing STEM fields because of sociocultural factors and are more likely than men to leave STEM fields (Ceci, Williams \& Barnett, 2009). It was only relatively recently that women 
This is an author-produced, peer-reviewed version of this article. The final, definitive version of this document can be found online at Journal of Business and Technical Communication, published by SAGE. Copyright restrictions may apply. doi: 10.1177/1050651917713253

were allowed into coed engineering programs, and historically their entry was denied or limited in educational spaces, let alone the workplace (Bix, 2013). And while some researchers question both the metaphor of the leaky pipeline and the attention paid to women leaving the field (Miller \& Wai, 2015), clearly the male-dominated engineering culture sends—and continues to reinforce- the message that women do not belong.

Historically, associating women with writing has been one way that the field has systematically isolated women from what was perceived as real engineering work as well as to silence and contain their contributions (see Connors, 1982; Kynell, 1996). Malone (2010) examined the historical case of one engineer, Lucille Pieti, who was diverted from engineering work into technical writing and then effectively marginalized and silenced when her employer obscured her expertise. Pieti's work for Chrysler from 1953-1955 put her on display at car shows as a physically attractive woman engineer who was knowledgeable about cars; as her fame grew, Chrysler began limiting her script, denying her control over what she could say. She left Chrysler to get married and later worked as a technical writer and engineer. While Pieti's case represents the experiences of only one individual, her story is consistent with the marginalization of women that occurred after World War II. These women were actively pushed out of maledominated STEM professions into less prestigious roles such as technical communication—or completely out of the workforce—even as women's enrollments in engineering programs grew (Bix, 2013; Malone, 2011; Rossiter, 1995). Malone has consistently worked to recover the historical contributions of women to technical communication, in line with Frost's (2016) call to use "apparent feminism" as a methodology for technical communication research that incorporates feminist perspectives.

To extend our understanding of what women experience as engineers in professional settings and how that contributes to their decisions to leave engineering as well as factors that might be used to retain them, I examine Katy's experiences as an engineer and writer, arguing that her standing as a skilled writer may have contributed to her overall dissatisfaction with engineering. While many scholars have examined the variety of factors that influence women's persistence in engineering as well as the reasons they leave, little work has examined how an engineer's identity and labor as a writer have an impact on retention. Katy viewed herself-as did her peers and supervisors - as a highly intelligent, capable engineer and writer. In fact, one major force behind her approach to writing and engineering work was her emphasis on efficiency defined by accommodating audience concerns and long-term needs. Katy's frustration with others' inefficiency or "satisficing" (Simon, 1969) motivated her to operate differently.

Discussing efficiency as a component of apparent feminism, Frost (2016) asked scholars to reconceive and redefine efficiency not just as achieving the greatest impact with the least amount of effort but also as accounting for human factors or user needs, conditions, and settings. She argues that "understanding efficiency as something that focuses on both energy expended and people affected, something that places primary importance on the human rights of stakeholders, might lead us toward altogether different practices." This approach pushes against "the disciplinary domination of male perspectives in technical communication-a domination that has been continuously reproduced in the name of efficiency" (p. 20). Frost stressed that technical communicators and research need to articulate the discipline's unapparent terms, such as efficiency, to allow for diverse views and work against injustice. Katy's struggle with writing can be viewed through her attempts to redefine efficiency as accommodating the needs of her audience rather than solely focusing on time or energy spent. In fact, her view of efficiency was bound up in her desire to be viewed as a competent professional in a male-dominated field, as well as to account for the range of her clients' needs. Her writing focused on what was valuable to clients, and its quality was recognized by her peers and professional organizations. ${ }^{1}$ But her struggle to create coherent meeting minutes demonstrates how this alternative understanding of efficiency is undermined by her peers' and supervisors' gendered perceptions of her writing.

\section{Methods}

Katy's story emerged from a larger project that explored the connections between women's experiences as both engineers and writers and their professional identities. ${ }^{2}$ Using an ethnographically informed case study approach, this study focused on four women from a range of engineering fields and at various career points (Mallette, 2015). While the sample size is small, the case study approach permitted an in-depth examination of a few individuals that accounts for context to address a descriptive or explanatory question rather than focusing on a breadth of information (Yin, 2009; 2012). Although case studies, which typically do not have a large number of participants, might not be able to generate data that allow a researcher to generalize findings broadly, they do permit an in-depth focus on context, 
This is an author-produced, peer-reviewed version of this article. The final, definitive version of this document can be found online at Journal of Business and Technical Communication, published by SAGE. Copyright restrictions may apply. doi: 10.1177/1050651917713253

individual experiences, and description unavailable with more quantitative methods (Lauer \& Asher, 1988; Yin, 2009). Case study findings can also be used to suggest directions for future research, including quantitative studies that may allow findings to be generalized (Lauer \& Asher, 1988).

Additionally, the context itself limits the number of participants available: Women are in the minority in engineering, which narrows the individuals available. To control for variables, possible participants were further restricted; for example, women whose first language was not English were excluded. All of the participants in this study were identified through networking; none of the women independently contacted replied to participation requests. Some women were possibly reluctant to become involved because of the time they believed the study would entail. In addition, they may have been reticent because of the threat posed by a writing researcher-a perceived writing expert-wanting to examine samples of written work. Because the culture of engineering can be one that encourages members to take up a nonwriting identity (Charney, Newman, \& Palmquist, 1995; Leydens, 2008; Winsor, 1996), this awareness of the researcher as a writing expert and the participants as somehow less skilled affected my interactions with the participants and are certainly present in the data. Katy herself pointed out that two factors influenced my interactions with potential participants: "(1) The intimidation factor and (2) seeing the lack of value in the research were foremost, being as how writing is embedded as an evil necessity but not prime value for engineers" (personal communication, March 30, 2016). After all, as Winsor (1996) pointed out, if writing is a practice that engineers supposedly inadequately perform, then embracing a writer identity could mean claiming not to be an engineer. And having someone study one's engineering communication would potentially mean having stereotypes about writing confirmed. Where possible, I attempted to account for these attitudes.

Since case studies involve situations, individuals, or occurrences that cannot be separated from their context, multiple forms of data must be collected, generally from within the participants' settings (Lauer \& Asher, 1988; Yin, 2012). For this study, primary data collection techniques included a series of interviews, observations, and writing samples. Interviews were conducted in three parts: an intake interview, an interview about each writing sample, and a final interview. Observations focused on watching the participant write and asking questions to prompt the writer to reflect on her writing choices, process, or content. Since Katy was employed outside the university settings where the other participants worked, I also interacted and conducted interviews with several of her coworkers and supervisors. In addition, I accompanied her on a site visit, observing a monthly project meeting. Except for the site visit, which spanned two days in a variety of settings, all interactions were recorded, and the interviews were later transcribed. Finally, member checks were conducted with the participants to ensure that my conclusions matched the participants' experiences.

In this article, I focus on Katy's case in particular to further explore her experience in a professional engineering setting. Although my focus on one participant limits my ability to generalize, Katy's experiences not only illustrate how writing might influence decisions to leave but also indicate future directions for examining writing in efforts to retain women in engineering. Because I worked most extensively with Katy, I was able to observe her writing more frequently and collect more writing samples from her than from the other participants. In addition, Katy and I knew each other before the start of this study, so she was more at ease with me and more willing to allow me to observe her and record our conversations. Given Katy's and my past relationship, she was less prone to bring up anxiety about her writing than the other participants. In fact, it was our early conversations about writing both within and outside of engineering that motivated this study.

Katy's engagement with writing and clear sense of herself as a skilled writer marked her as unique in a field in which being (or at least claiming to be) a poor communicator is culturally acceptable. While the Accreditation Board for Engineering Technologies (ABET) and employers have recognized the demand for skilled engineering communicators (Lattuca, Terenzini, \& Volkwein, 2006), the culture surrounding engineering practice permits "good enough" writing to be used—or satisficing to occur-even if the end product is not as effective as it could be. Coined by Simon (1969), satisficing is a term that combines satisfy and suffice to refer to "decision methods that look for good or satisfactory solutions instead of optimal ones" (p. 64). It has been used in economics as well as other fields to explain decisionmaking phenomena. I use it here to refer to the decisions made by engineering communicators to create sufficient writing that is not necessary optimal. In addition to accepting satisficing in writing, engineering practitioners often call attention to their own "lack" of writing or verbal communication skills, further underscoring their belief in the stereotype that engineers are poor communicators (Charney, Newman, \& Palmquist, 1995; Winsor, 1996). 
This is an author-produced, peer-reviewed version of this article. The final, definitive version of this document can be found online at Journal of Business and Technical Communication, published by SAGE. Copyright restrictions may apply. doi: 10.1177/1050651917713253

Given the effects that cultural beliefs can have on the members of a particular community of practice, Katy's tendency to rate her writing highly sets her somewhat apart from the typical engineer. She might comment that she always felt like she could learn more about writing or that she often considered ways to improve her writing, but she believed that she was a stronger writer than her coworkers were and likely a stronger writer than the majority of peers. In addition, her writing was rooted in her refusal to satisfice and her understanding of efficiency as more than energy expended. As I argue later, Katy's dissatisfaction arises from her belief that satisficing is inefficient based on her understanding of efficiency as accounting for human factors and action, a rearticulation of efficiency that Frost (2016) examined as an element of apparent feminism.

\section{Findings}

As a professional engineer, Katy was the only woman at her workplace who was not administrative staff; on job sites, she was often the only woman besides the administrative assistants among the various contractors, clients, client staff, and other engineers. While she generally felt comfortable in these settings, she recalled a number of occasions where she was made painfully aware of how others viewed her first as a woman rather than as a competent, professional engineer. For instance, Katy was present when a contractor began complaining about another woman on the project, commenting that women were difficult to work with because they are emotional and irrational. When she confronted him, asking “Am I emotional? Am I irrational?", he admitted that she was neither. He might have meant those comments to be directed at her, however, and did not expect her to speak up. As Katy explains:

The story you've heard me tell about the guy - this specifically in construction engineering which touches a lot of engineers-is working in the field with jackasses who are sexist. That's really difficult. Being told that women are hard to work with in construction because we are emotional is really demeaning. So I obviously experienced that totally different...That comment would never have been made if it was just a man to a man, a man to another man. Even though the comment wasn't $100 \%$ directed at me, it was obviously directed in some fashion at me. So yeah, just little things like that, is just insulting. (personal communication, December 17, 2014)

Such remarks are not out of the ordinary in Katy's experience and even when they are not directed at her, she understands that they meant to apply to her generically as a woman.

Katy was also angry and frustrated because no one else in the room- her coworkers-put an end to his inappropriate remarks or stood up for one of their own. Perhaps they did not realize that Katy heard the contractor's complaints about a particular woman as about all women, including herself, but ultimately his behavior was still inappropriate. In this situation, her coworkers either were unconscious of the impact of the contractor's statements or heard it as typical for the kind of male-dominated setting they were in and preferred not to confront the speaker. Their silence reified the hostile environment and culture of misogyny that Katy knew construction engineering to be. Even after Katy reported the incident, her coworkers insisted that it was just humor, minimizing and dismissing her concern. This culture has a significant impact on women's experiences in the field and also directly affects their retention in engineering (Yates, 2001). While perhaps an extreme illustration of the belief that women cannot work well with men, particularly outside the office in construction settings, other exchanges were more subtle indications of this view, and they add to the sense that women are not welcome.

By the time we began working together, Katy was highly dissatisfied with her work as an engineer and was actively transitioning to career path outside engineering. While many reasons accounted for her frustration, I focus here on Katy's writing as a location that reveals her dissatisfaction for two main reasons: because writing was not valued as engineering labor and because others in her firm did not seem to embrace her approach to efficiency that led her to account for audience needs and to refuse to satisfice. Since Katy considered writing as part of her professional identity as a civil engineer, any dismissal of her attempts to act through writing contributed to her overall negative perceptions of her profession. Two separate projects and the writing created within those projects (and rhetorical situations) demonstrate the connections between writing, Katy's professional identity, and her dissatisfaction with her firm and the field. At the start of the study, Katy was a project engineer for a large wastewater treatment facility that had been under construction for several years. This project required producing several genres of writing, including less formal types such as meeting minutes as well as more formal genres such as the plant's operations and maintenance (O\&M) manual. Toward the end of this study, she also crafted a preliminary engineering report for a city exploring the possibility of constructing a composting facility. 
This is an author-produced, peer-reviewed version of this article. The final, definitive version of this document can be found online at Journal of Business and Technical Communication, published by SAGE. Copyright restrictions may apply. doi: 10.1177/1050651917713253

Here, I examine two different documents—-the minutes and the report-that she composed throughout the study in response to two particular rhetorical situations. While Katy spent a significant amount of time on these documents, her labor was frequently overlooked or undervalued, further underscoring her dissatisfaction with her workplace and with the chances of using writing to do anything. Katy embraced a definition of efficiency aligned with Frost’s (2016) argument that technical communication researchers should examine implicit understandings of efficiency that go beyond energy expended and move toward an understanding of diverse audiences and users. Unfortunately, Katy's understanding of efficiency was often at odds with her coworkers' approaches, creating conflict and contributing to her dissatisfaction.

\section{Meeting Minutes and the Value of Writing Labor}

The monthly meeting minutes Katy produced represent much of what was problematic about her role on the project and her interactions with several individuals in her firm. The minutes also reveal the status of writing labor in her organization, a status that echoes historical attitudes toward written text in engineering disciplines (Longo, 2000; Malone, 2010). For Katy, the meeting minutes initially were a site for asserting her authority as a competent professional, but later they devolved into a less effective format due to competing demands within her organization. The conflict emerged from two competing views on what meeting minutes should do. Bob, one of the firm's principles (an owner of the company and therefore above Katy in the organizational hierarchy) who had taken over managing the project, believed they should be a complete record of precisely what was said during the monthly meeting in case legal issues arose. Katy disagreed with this approach and argued that the minutes should concisely summarize the meeting's main discussions to give readers a brief overview of what took place and what should occur before the next meeting. She would eventually give up trying to convince Bob, who had effectively stripped many of her responsibilities on the project, to accept most of her attempts at improvement, settling for a compromise between a more detailed transcript and a usable document for the primary audience.

While meeting minutes were generated to meet state-reporting requirements and for legal uses, Katy believed their primary function was to manage the project effectively — though not in their transcript-style form or with the method that the firm traditionally used to construct them. For the first several years of the project, the meeting minutes were created by an administrative assistant, who would transcribe the meeting recording, more or less writing down everything that was said as it was said, even if it was off-topic, irrelevant, or poorly stated. This transcript would often be 20 or more single-spaced typed pages. Katy would then revise that transcript into something coherent and more simplified, although she chafed at the task because it was time-consuming and often unrecognized labor. This composing method was inefficient, and her revisions consumed more than 8 hours of her billable time (as well as a day and a half of the administrative assistant's time) that she felt could be better spent doing other engineering work. More importantly, the resulting documents were infrequently used by the various recipients because they were long and cumbersome. The final minutes were still lengthy-even revised, they totaled 8 or more single-spaced pages containing large blocks of uninterrupted text. One month the minutes were sent out without Katy's review, and they were 20 pages of unrefined text that represented a complete transcript of the meeting.

Both the length and transcription approach likely prevented most readers from reviewing the minutes, thereby rendering them ineffective and inefficient because they accomplished little. As Katy commented, "I think everyone that gets [the minutes] was [in attendance], so I think they're probably not like 'ooh, let me relive that by reading these 10 pages of minutes'” (personal communication, November 1, 2013). Recognizing that efficiency relates to user needs, she felt that no one would be eager to relive the meeting, so no one would likely review or use the minutes once they were distributed. The minutes were thus inefficient in this format, even if they technically took less time to generate. Katy also pointed out easily avoidable errors that were incorporated into the transcript. For instance, the administrative assistant transcribed one statement as "[Katy] asked about a crossword puzzle [emphasis added]" (personal communication, November 1, 2013) when the correct phrase was cost proposal. Clearly, crossword puzzle made little sense in the context of an engineering project meeting, yet the administrative assistant did not seem to be able to make the judgement call or to confirm what she heard. Katy's awareness that the minutes were inefficient not only in the use of company time but also in usability pushed her to try to change the firm's approach to producing the minutes despite resistance from one of the firm's principles, Bob.

Katy resisted the transcript approach because she knew it was ineffective and inefficient for the user, and she attempted to shift the minutes to be more action oriented. While minutes can be overlooked as a less important writing genre in engineering settings, effective minutes can be beneficial for enhancing communication and outlining future action that 
This is an author-produced, peer-reviewed version of this article. The final, definitive version of this document can be found online at Journal of Business and Technical Communication, published by SAGE. Copyright restrictions may apply. doi: 10.1177/1050651917713253

should take place as the result of the meeting (Wolfe, 2006). Wolfe (2006) examined the rhetorical nature of meeting minutes and how they are used by professionals in ways not accounted for by technical communication textbooks. She categorized minutes into three style types: transcriptional, essentially containing everything that was said in chronological order with little use of formatting; action-oriented, using formatting such as bullets and headings to outline what needs to be completed; and parliamentary style, following Roberts Rules of Order, which is used in government and academic settings (Wolfe, 2006).

Katy's firm used the transcript style, which Bob preferred, yet as Wolfe noted, such minutes not only take substantial time to compose but also do "little to focus the team's efforts" (p. 355). In other words, transcript-style minutes are inefficient in both time expended and action generated. The professional managers Wolfe (2006) interviewed stressed how effective minutes, particularly action-oriented, can create consensus, structure future meetings, and allow managers to follow through on the decisions made to ensure those actions are accomplished. Most important, these minutes cannot be produced by a secretary or administrative assistant because they lack knowledge of the subject or context to make appropriate decisions about what should be included. Wolfe's findings are consistent with the changes that Katy attempted to implement: Katy wanted minutes that could highlight the essential information and spur future action or that were rhetorically useful.

Partway through this study, Katy successfully negotiated to create the minutes not from the typed transcript but by listening to the recording herself in order to align the genre with action-oriented meeting minutes. Katy responded to my analysis by explaining why she thought her negotiation was ultimately successful:

This was after much arguing with Bob and even going to [the company's president] about the issue and how I felt it could in fact get us in legal hot water (and made us look like idiots). Bob finally relented only because he 1) was tired of me trying and 2) I got the strong suspicion that it would either be further punishment and happily alleviate the assistant from having to do it, and/or I would fail somehow. (personal communication, March 30, 2016)

She also clarified that Bob required a change in the name of the document, potentially to underscore that he felt they were not true meeting minutes: "From this point on, Bob insisted that the minutes were not minutes, but 'meeting notes' and retitled the heading of the document as such” (personal communication, 30 March 2016).

The process shifted from editing down a large amount of text—much of it inessential—to only writing down the essential ideas. This change in the writing process affected the end product by enabling Katy to write in a more concise style that better matched the standards of technical communication (see, e.g., Tebeaux \& Dragga, pp. 57, 62). Thus Katy, who constantly stressed the need for efficiency, was able to produce the minutes more efficiently both by using less energy and by factoring in human needs as Frost (2016) emphasized in her definition of efficiency. Here is an example in the Project Scheduling section of the original transcript-style minutes prior to Katy's revision:

[Bob] discussed cut-off of Friday, October 25th and noted the monthly meeting for November had been changed to Thursday, November 7th. The cut-off date in November will be the day after Thanksgiving (Friday, November 29th) and stated that he doesn't think we will change the meeting date in December adding that things just get crazy and there is not a place to put it. With that being the case, the cut-off is November29th [sic] and the monthly meeting will be on Thursday, December 12th. The cut-off date for the disbursement is the next day, December 13th and inquired if [the contractor] was still good with that adding that [the contractor] would have it the day of the meeting. Summarized dates are as follows: [table listing the dates].

This quotation from the original minutes illustrates what Katy was working against. The document neither a verbatim transcript nor usable meeting minutes, but instead was a mostly verbose, convoluted, and often syntactically confusing text. This version also presents a number of issues that do not adhere to effective and efficient technical communication, such as obscuring the key idea (the changes to the November cutoff date and meeting). In addition, this version contains potentially confusing and less-than-professional phrasing, such as "things just get crazy and there is not a place to put it." Much of this text is essentially a prelude to the table containing dates that the readers need, but the essential information is lost within the verbose and confusing discussion transcript making it an inefficient text for readers. To make the content more readable and concise, Katy significantly revised it, attempting to convey the primary idea: 
This is an author-produced, peer-reviewed version of this article. The final, definitive version of this document can be found online at Journal of Business and Technical Communication, published by SAGE. Copyright restrictions may apply. doi: 10.1177/1050651917713253

[Bob] discussed cut-off and monthly meeting dates. As discussed previously, only the meeting dates for November were changed from those originally scheduled. Summarized dates are as follows: [table listing the dates].

Katy understood that it was unnecessary to discuss why the changes took place or what the dates were (that information was conveyed in the table) so she reduced the rambling commentary to the primary idea-that the meeting date in November was altered from the original schedule. She reduced 121 words to 27, giving the reader something more manageable to review. Her revision also exhibits the standards of effective technical writing with its shortened sentences, more concise phrasing, and emphasis on the information the reader needs. This revision, then, is more efficient not only because it uses fewer words but also because it accounts for the needs of the readers.

The change in the drafting process also meant that Katy was able to enhance her own efficiency by reducing the time she spent creating minutes that were useful and usable by the individuals involved with the project. A comparison of a similar section from (a) the original, transcript-style minutes, (b) Katy's revision of that original text, and (c) the minutes Katy was solely responsible for producing demonstrates the impact of her no longer being inhibited by the original, transcript-style document. Here is a selection from the Submittals section in the original text:

[Bob] stated that he wanted to take a quick look at the submittals and a copy of the submittal log was disbursed. [Bob] indicated that items 1-5 (should be 1-6) are O\&M Manuals. [Bob] continued stated [sic] that items 7, 8, \& 9 if he understood correctly that [architect] would be in [City] next Thursday (October $17^{\text {th }}$ ) to deal with all of the color issues.

Again, the method of transcribing everything that was said is unusable by a reader and verges on unprofessional, particular in the phrases "take a quick look" and "deal with all the color issues," which represent a conversational register appropriate at a meeting but not in documentation. Katy's revised selection is much clearer, more professionally worded, but still less concise than she would prefer:

[Bob] distributed copies of the submittal log. [Bob] indicated that 6 submittals were O\&M Manuals and 3 were architectural. [Bob] indicated that [architect] would be on-site October $17^{\text {th }}$ to meet with [contractor] regarding color determinations, at which time [contracting company] should have provided colors for selection.

Again, Katy uses revision to more clearly convey the essential elements of what was discussed and to alter the tone to be more professional and concise. One of Katy's complaints about the minutes were that they were unprofessional, even "embarrassing": "I wouldn't want it to leave the office and be distributed to other people because of the nature of the language" (personal communication, November 1, 2013). Because the minutes represented her professional identity, she took care to revise the language to what she felt was less colloquial and more professional.

Once Katy began creating the minutes from listening to the recording instead of revising the "embarrassing" typed transcript, she significantly altered the overall format of the minutes. Here is a sample of what a reader now encountered under the Submittals section: "Copies of the submittal log were disbursed and discussed." Because the person who disbursed the copies was less essential to the reader than the dispersal — the reader need only know that the log was distributed to the meeting participants-Katy was able to more concisely state that action to save space for other information. She then broke up the discussion of the submittal log items into separate sections, whereas before they may have been contained in one larger section. This separation allowed Katy not only to better organize the discussion but also to navigate the reader to the information they require. In addition, she followed each section up with action items to highlight what needed to occur prior to the next meeting. For instance, under the Insulation section, Katy provided a more detailed summary of the discussion, followed immediately by an action item that looks ahead at what should occur:

[Architect] and [contractor] discussed the insulation material information provided by [contracting company]. It was established that two separate subcontractors would be installing cellulose installation (acoustic vs. thermal). [Architect] noted that the provided documentation was applicable only to the acoustic wall insulation and not the thermal perimeter application. [Architect] stated that the documentation did not include information regarding the stabilizing additive and noted a discontinuity in the ASTMs cited versus that specified.

ACTION ITEM: [Contracting company] to provide additional information to [engineering firm] for the thermal installation. [Architect] to correspond with [contractor] regarding insulation documentation provided. 
This is an author-produced, peer-reviewed version of this article. The final, definitive version of this document can be found online at Journal of Business and Technical Communication, published by SAGE. Copyright restrictions may apply. doi: 10.1177/1050651917713253

Although Katy believed she still included more information than was necessary or efficient for the reader, altering the composing process allowed her to take control over the minutes' content, writing style, and formatting. The new drafting process allowed her to better accomplish a specific purpose: not only to communicate the events of the meeting but also to remind the various parties and stakeholders what action they needed to take. Just by skimming the document, the reader could focus on the action items and still understand what needed to happen in the next month. In fact, Katy commented that despite Bob's misgivings over what he saw as a lack of detail, he used the action items to set the agenda for the following month's meeting, indicating that the minutes were being used to manage the project more efficiently. Katy's use of action items also highlights her focus on the rhetorical nature of minutes as, Wolfe (2009) discussed, that move them from being a record of what was said to an indicator of future action.

While these changes seemed to be well received by those involved with the project, her conflict with Bob eventually led Katy to step back from her effort to craft a more usable document. This conflict emerged from two sources: disagreement over what the meeting minutes should primarily do as well as disparate beliefs in what constitutes engineering labor. While Katy saw minutes as a managerial document to prevent misunderstandings and direct future action, Bob saw minutes as a representation of what was said during the meeting that could have legal uses. In other words, Katy looked to the future whereas Bob focused on the past. Bob's continued insistence on precisely capturing what was said reveals his concerns over lawsuits and any potential disagreement or misunderstanding between the engineering firm and the contracting company. Yet in his desire to avoid litigation, Bob overlooked how meeting minutes can produce action, a more immediate and efficient use for the readers. While Katy also recognized the legal implications of the documents - in fact, she repeatedly warned the firm's principles that they were potentially headed toward a lawsuit with this project-she knew that the minutes were not the writing space to focus on legal concerns. Instead, she understood the potential for action when she not only altered the writing process to be more efficient but also shifted the content to be more usable by a reader. Her addition of the action items and clearer section headers acknowledges the recipients' reading conditions: Readers of the minutes are in a hurry, and they want to easily find useful information. While her version of the minutes does not provide a complete transcript of the conversation that would be useful in legal contexts, it is more usable for readers because it attends to the more pressing and immediate concerns in construction management.

More significantly, the conflict over and attitude toward meeting minutes revealed that Bob, and perhaps others in the company as well as those involved with the project, viewed these forms of writing as nonengineering labor. In other words, the minutes were seen, at least by Bob, as a necessary legal document but not a form of engineering discourse, even though they needed to be written by an engineer. In fact, Bob felt that they could be written by a nonengineer, specifically the administrative staff. Organizationally, it was standard for minutes to be produced with an administrative assistant playing a major role in their drafting, which Katy found so frustratingly inefficient. This longstanding association of the minutes with the administrative assistant implies that organizationally, minutes were not necessarily recognized as engineering labor. ${ }^{3}$ Other factors also lead to this conclusion. For one, Bob attempted to reassign the writing of the minutes, cutting Katy completely out of the process. Because the reassignment would further reduce Katy's role on a project she was supposed to lead, she resisted, which resulted in her efforts to reshape the genre.

Another factor is that Katy alone seemed to be concerned with how the minutes appeared to readers. She was aware that no one else seemed to give them the same attention: "I feel like they need to be done, and they need to be done well if we're going to submit them. So I take that upon myself to make it happen. And I probably put way more effort into it than I probably need to." In fact, when Katy was unable to edit the minutes one month, and Bob reassured her that he would take over the task, the minutes were submitted nearly unrevised, implying that he believed they were not worth his effort. Katy commented, "I was kind of horrified, to be honest" (personal communication, November 1, 2013) because for her, the unrevised minutes did not convey the level of professionalism and even efficiency that she aspired to portray through her professional practice.

Finally, even after Katy took over the drafting, Bob continued to route final edits through the administrative assistant. These factors together sent a message about what he did and did not value as engineering labor. In this case, he did not seem to appreciate that composing meeting minutes and spending time attempting to improve them as a usable document was a valuable skill. Furthermore, despite his use of the action items in setting meeting agenda and managing the project, Bob's resistance to Katy's changes to the minutes led her to succumb to pressure to retain an inefficient, unnecessarily descriptive approach by dropping her push to improve the minutes. 
This is an author-produced, peer-reviewed version of this article. The final, definitive version of this document can be found online at Journal of Business and Technical Communication, published by SAGE. Copyright restrictions may apply. doi: 10.1177/1050651917713253

For Katy, the minutes came to represent many of her frustrations with the project. Katy resisted Bob’s attempts to reassign the task elsewhere not because she particularly wanted the task-though she knew she was likely the only one who would do it satisfactorily let alone to her high standard—but because she saw the reassignment as part of a pattern of reducing her role. When the project began, she was the design engineer and was meant to be the lead engineer, but one of the firm's principles ended up adding himself to the project. Katy had already seen so many opportunities to learn about how to run a project slip away, so she resisted when the removal of another major task threatened her involvement. Her work with writing the minutes thus represents the struggles she endured with Bob over the use of project documentation and her desire to represent herself as a committed, competent, and efficient engineer. To see her writing labor reduced or dismissed was akin to questioning her ability, and it further fueled her dissatisfaction with her firm and with the engineering field as a whole.

\section{Preliminary Engineering Report and Efficiency}

While the meeting minutes reveal the cost of producing writing that is essentially ignored or not considered "real" engineering work, preliminary engineering reports demonstrate another potential way that writing creates dissatisfaction. For Katy, the report she wrote investigating a municipal composting facility was initially exciting because it was a new type of project offering new learning opportunities. But, before Katy and her mentor (her direct supervisor) could present the research detailed in their preliminary engineering report, the city cancelled the meeting. For months, the report—and all the research and writing Katy had produced—languished, potentially consigned to the pile of engineering reports Katy had written that never progressed beyond the preliminary phase. Although Katy explained that it is not uncommon for one firm to be hired to create a report and another firm to be hired to design and build the project, she also pointed out that she felt as if she had written more than the average number of reports that never moved into the next phase, especially at the beginning of her career. Occasionally, she felt discouraged at never seeing her research and problem solving result in tangible products valued in engineering. For this composting facility project, the report was shelved for several months before the city considered hiring Katy's firm to design the facility and solve a major problem she had discovered. However, by that time, Katy was only working part-time and was planning to leave the firm as soon as her own company was viable. Eventually, the city would publish "a bid process seeking contractors to perform the type of project which we were cautioning against" (personal communication, March $30,2016)$, generating a situation where extensive research and writing proved ultimately ineffective in attaining the solution she argued for.

This lifecycle of preliminary engineering reports is typical in civil engineering. As Katy explained, while a firm might be hired to conduct preliminary research for a project, they might not be hired to conduct the design and build phases. Frequently, reports are written simply to be shelved, opened again only if they provide a template or information useful for the next project an engineer is assigned:

I think a lot of kids think, "Oh I'm going to go into math, I'm going to go into engineering, and I won't have to write ever," which is absolutely incorrect. I think I was able to pick that up a little bit in school, but maybe didn't realize just to the extent, yeah you're going to write reports more than you're going to be doing design work. Because it may just take you a small amount of time to come to a design conclusion, but then you have to put that in writing for, say, a city council or a commission-you have to explain the whole process to them, which might be really easy to you, but you've got to put it in a layman's terms and that can take a very long time if you're starting from scratch. (personal communication, November 7, 2013)

Because she was aware that she might spend more time researching and communicating than conducting what is more typically perceived as engineering work, Katy did not resist writing. She seemed to generally view writing as integral to her work as an engineer, and she carefully considered how she could use the report as an opportunity to argue for a solution. Her belief in the value of arguing for solutions was influenced by her belief in efficiency as accounting for human motivations (Frost, 2016) and her refusal to satisfice. In the end, it was more efficient for Katy to spend time researching solutions and crafting a well-written report if it meant that the client was able to understand the information presented-whether it progressed to the next phase or not.

In fact, Katy pointed out that another benefit of being thorough is that engineers frequently use past reports as a source of information. She often remarked that she was writing for herself in case she needed to refer back to the report years later. She commented, "I definitely pulled off some reports from 15-40 years prior and thought either 1) 'Dammit, why couldn’t you have provided more info' or 2) ‘Nice, there’s the information I need in here that will save me loads 
This is an author-produced, peer-reviewed version of this article. The final, definitive version of this document can be found online at Journal of Business and Technical Communication, published by SAGE. Copyright restrictions may apply. doi: 10.1177/1050651917713253

of time/work.' Never did I think, 'Wow, this report is too detailed’” (personal communication, March 30, 2016). Thus, her refusal to satisfice was rooted not only in her own work ethic but also her belief in her professional ethical obligations and her understanding of how reports are used beyond a single project. If she did just the minimum required, her work would be inefficient not only because it did not communicate clearly, but also because it did not give the client what they were paying for. It also would make her (or another engineer's) future work more difficult. This understanding of the power of engineering communication - to advance recommendations to clients, to convey information efficiently and clearly, and to fulfill professional obligations-shaped her work with the preliminary engineering report for the composting facility.

But Katy also understood a major drawback in doing so much writing: She was unable to learn more about design and practice those skills if she spent all her time writing meeting minutes, preliminary reports, and other engineering documents. In fact, because she was seen as a skilled writer in her firm, she often took on more of the writing labor, occasionally being assigned writing tasks that were originally another's responsibility. She explained how writing can inhibit her engineering work:

I feel like [when] I write more than I design, I'm losing those skills. So I don't practice as much design work whenever I'm spending a month writing a report. I mean I get some, to get the information in here, but I feel like I focus a lot of energy at something that's also presentable, and also probably more energy than some people that I know, like peers or people in my office, so that's the other thing that hinders. But again, that's kind of the end game. That is the goal. Or not an end goal to write the report, but to get the thing done. (personal communication, December 17, 2014)

Her comments reveal some of the tensions that existed for her between writing and design work within an engineering setting. On the one hand, Katy is aware that "the end game" is to "get the thing done," and writing is part of that. On the other, she acknowledges that she expends more energy crafting her writing, at least compared to her peers at the firm. Because writing is central to Katy's professional identity, she is not content to satisfice and write the "good enough" report; instead, she must create an outstanding report. Her writing is recognized by her peers and by professional organizations as exceptional; she is the only one in her firm to have won awards for her writing. Dedicating so much of her energy to writing, however, leaves Katy with the sense that she is unable to direct her focus toward the design work that is more visibly engineering labor and on the further development of her technical skills.

This tension between her writing and her design work, then, is a factor in Katy's dissatisfaction with the engineering field. By asserting that she is a highly capable writer, likely more skilled than her peers and certainly recognized for her writing ability, Katy becomes associated with writing. She is then assigned more writing than others might be. Her personal work ethic and high writing standards keeps her from satisficing or taking shortcuts in drafting a report or document, so she commits a significant portion of her professional time and energy on writing. In her commitment to efficiency in relation to human actors and her desire to demonstrate a high level of competence, Katy writes reports that come to represent who she is - that is, the report is a projection of Katy's work ethic and her writing and technical ability. For Katy, who believes that the more she writes the less she engineers, a report that never moves beyond the preliminary phase becomes an instance of failure. And while failure is part of engineering practice (Petroski, 1992), repeated failure can be frustrating; thus, the addition of preliminary report for the composting facility to the pile of reports that never went to design created another moment of dissatisfaction for Katy. Despite Katy's refusal to satisfice and her care in constructing an efficiently, thoroughly researched, and well-written report, the project never progresses.

Katy especially felt the loss of this project because while she was already unhappy in her position and planning to leave engineering, the project itself piqued her interest. It represented an opportunity to form a new set of skills and explore a new type of project. As an intellectually curious person, Katy viewed the project in terms as an opportunity to acquire new knowledge, to solve a major problem that others had missed, and to help the city pursue a sustainable course of action. In fact, in researching and developing the preliminary report, Katy discovered a problem that the city itself had overlooked and brought it to the city's attention. Initially, her discovery put the whole project on hold while the city dealt with the problem - the city did not contact Katy or her firm for some time-but her hard work and persistence resulted in the city's eventually reinstating contact and seeking to work with the firm. In the end, however, the city chose a different company. The possibilities that the project offered faded, and the preliminary report became yet another artifact to be shelved. 
This is an author-produced, peer-reviewed version of this article. The final, definitive version of this document can be found online at Journal of Business and Technical Communication, published by SAGE. Copyright restrictions may apply. doi: 10.1177/1050651917713253

\section{Conclusion}

As an exceptional engineer, Katy's choice to leave engineering might be mourned both because it is a loss of a skilled designer and communicator and a failure to retain yet another woman engineer. While it would be problematic to see her quest for a satisfying career as just another statistic, we also cannot ignore the numerous factors that influenced her to leave engineering. For Katy, a major impetus to leave was a sexual harassment incident she experienced that her firm did not handle appropriately, which made her workplace feel hostile and unsafe. But even before this incident, she had become dissatisfied with her job, finding it emotionally draining and frequently upsetting. Combined with the sexual harassment she had experienced, this dissatisfaction influenced her decision to leave the field. Her writing serves as a location to examine the overlap of many of those factors. From her firm's resistance to accept the improvements to the monthly meeting minutes to her feelings of failure over preliminary engineering reports that never progressed, we cannot ignore the influence of writing on Katy's retention in the field.

While this article analyzes the role that writing payed in Katy's dissatisfaction with engineering, her use of writing to accomplish action reveals potential positive uses. Researchers and teachers such as Ford (2012) have offered ways to better incorporate writing into engineering that do not reify the science-humanities binary. For instance, because of her dual role as a member of both an English and a mechanical engineering department, Ford was viewed as an engineering insider whose work with communication belonged within engineering practice. If the binary between STEM and liberal arts fields can be disrupted, what are the possibilities for writing as a tool for retention in STEM fields?

One implication is that if communication is to be recognized as just as much a part of engineering as is technical labor, then the culture of engineering must shift away from dividing the two. This division begins early in the sciencehumanities binary and is carried out in many engineering settings-from university courses to academic and professional settings. The university classroom can begin to undermine the artificial split between communicative and technical skills by doing more to integrating writing and technical engineering content more consciously into the course than simply assigning a writing task or occasionally bringing in a writing expert to speak to students. As Wolfe and Alexander (2005) demonstrated, women often take on more writing labor than men do, which is overlooked in favor of skills perceived as more technical (e.g., computer work). If engineering instructors are conscious of this division of labor when assigning group projects that entail both writing and technical work, they can make students more aware of the field's undervaluing of writing as well as women's tendency to take on that work. In addition, instructors can require that everyone contribute equally to writing tasks, acknowledging overtly that writing is as valued as design and calculation and ensuring that women are not solely responsible. Engineering instructors can also evaluate projects in a way that demonstrates that engineering does not perceive communication skills solely as a tool to convey technical information.

Furthermore, scholars and teachers in rhetoric and composition can collaborate with engineering department to build on the research that examines gendered interactions in engineering classrooms. Not only can these collaborations undermine disciplinary boundaries, they can begin to change long-held attitudes toward writing and the ways communication skills and efforts tend to be devalued.

For instance, Wolfe and Powell (2009) examined how speech acts associated with women—such as using I-statements to frame criticism - are seen as weaker than male-typical speech acts that are viewed as more direct. These subtle biases toward women's communication send the message that women do not belong in engineering and reinforce the unapparent ideologies in technical communication that Frost (2016) exposed. Referring to the dangers of leaving the term efficiency unarticulated in technical communication, Frost (2016) argued that "anyone who can be labeled as inefficient is a threat to the status quo." Furthermore, when a term such as efficiency is "so embedded as a culture value that it is no longer explicitly discussed ... it is then a small step to using efficiency to justify racism, sexism, ableism, and other evils" (p. 17). Besides efficiency, other values embedded in the culture of engineering that affect both the perceptions of women's communication and the ways labor is viewed and valued must become articulated to enact change and correct injustice. By facilitating conversations about unarticulated understandings of concepts such as what constitutes direct communication or efficient work, engineering and writing scholars can work together toward the goals of apparent feminism to undo or undermine unquestioned ideological assumptions that affect women and minorities more negatively than men. More work needs to be done in this area to continue changing engineering culture. 
This is an author-produced, peer-reviewed version of this article. The final, definitive version of this document can be found online at Journal of Business and Technical Communication, published by SAGE. Copyright restrictions may apply. doi: 10.1177/1050651917713253

In addition, scholars in technical communication and composition must recognize that for women especially, writing is not unequivocally a path to success. Katy is a highly skilled, talented engineer, yet her writing ability did not pave the way for her professional advancement or satisfaction. In fact, she believed that her communicative ability would unlikely not allow her to advance, and as I argue, it factored into her job dissatisfaction. She also asserted that her writing ability caused her to be assigned more writing and given less design-related tasks, and design is what engineers are most frequently rewarded for because it is more tangible and visible than is the often-invisible writing labor. Thus, better recognition of the role of writing for women engineers will not alone add to retention efforts, but by studying this under-examined factor, we can explore the many reasons women leave engineering-or might decide to stay. Future research should continue to study the role of writing in how engineers develop a professional identity, how it might function to position women outside engineering practice, and what possibilities it offers for recruitment, advancement, and retention.

Although Katy's individual experiences cannot possibly stand for every woman's experience in engineering, her case opens the doors to explore how writing may work for or against women's retention. Katy sought to write well because her personal work ethic and desire to be perceived as a highly competent professional would not allow her to satisfice, and she was able to advance alternate ideas of efficiency that undermine the male-dominated perspective (Frost, 2016). Exhibited elsewhere, this drive would lead to professional success, yet this drive as demonstrated in her writing role led to her frustration with her career, her conflict with other individuals in the firm, and her belief that her efforts were in vain. While she did find writing satisfying at times and was rewarded for her skill, this skill became part of the larger situation that caused her to decide to leave engineering. A clearer understanding of the role writing might play in women's decisions to leave-or remain-in engineering disciplines will allow us to identify at-risk women and find avenues to alter engineering culture. Ultimately, writing has a place in the larger matrix of engineering practice and should be considered as an aspect in retention.

\section{Notes}

1. Katy is the only individual in her midsized consulting firm to have ever won an award for writing, and she has been recognized by engineering organizations at both the state and national level.

2. This research was conducted with approval from the Institutional Review Board at the University of Arkansas, and each participant was provided an informed consent form that detailed the research procedures and their involvement.

3. That women administrative staff drafted the minutes and male engineers did not implies that the task was perceived as gendered labor. Katy's male peers were not as invested in making sure that the minutes were written correctly, and she alone went to the trouble to make sure that they were more than just a document that fulfilled a state legal requirement.

\section{References}

Bix, A. S. (2013) Girls coming to tech! A history of American engineering education for women. Cambridge, MA: MIT Press.

Burke, R. J. (2007) Women and minorities in STEM: A primer. In R. J. Burke \& M. C. Mattis (Eds.), Women and minorities in science, technology, engineering and mathematics: Upping the numbers. (pp. 3-27). Northampton, MA: Elgar.

Burke, R. J., \& Mattis, M. C. (2007). Preface. In R. J. Burke \& M. C. Mattis (Eds.), Women and minorities in science, technology, engineering and mathematics: Upping the numbers. (pp. x-xvi). Northampton, MA: Elgar.

Ceci, S. J., Williams, W. M., \& Barnett, S. M. (2009). Women's underrepresentation in science: Sociocultural and biological considerations. Psychological Bulletin, 135, 218-261.

Charney, D., Newman, J. H., \& Palmquist, M. (1995). “I'm just no good at writing”: Epistemological style and attitudes toward writing. Written Communication, 12, 298-329.

Connors, R. J. (1982). The rise of technical writing instruction in America. Journal of Technical Writing and Communication, 12, 329-352.

Dean, D. J., \& Fleckenstein, A. (2007). Keys to success for women in science. In R. J. Burke \& M. C. Mattis (Eds.), Women and minorities in science, technology, engineering and mathematics: Upping the numbers. (pp. 2844). Northampton, MA: Elgar. 
This is an author-produced, peer-reviewed version of this article. The final, definitive version of this document can be found online at Journal of Business and Technical Communication, published by SAGE. Copyright restrictions may apply. doi: 10.1177/1050651917713253

Ford, J. D. (2012). Integrating communication into engineering curricula: An interdisciplinary approach to facilitating transfer at New Mexico Institute of Mining and Technology. Composition Forum, 26. Retrieved from http://compositionforum.com/issue/26/new-mexico-tech.php

Frost, E. A. (2016). Apparent feminism as a methodology for technical communication and rhetoric. Journal of Business and Technical Communication, 30, 3-28.

Kynell, T. C. (1996). Writing in a milieu of utility: The move to technical communication in American engineering programs, 1850-1950. Norwood, NJ: Ablex.

Lattuca, L. R., Terenzini, P. T., \& Volkwein, J. F. (2006). Engineering change: A study of the impact of EC2000. Baltimore, MD: ABET. Retrieved from http://www.abet.org/wpcontent/uploads/2015/04/EngineeringChange-executive-summary.pdf

Lauer, J. M., \& Asher, J. W. (1988). Composition research: Empirical designs. New York, NY: Oxford University Press.

Leydens, J. A. (2008). Novice and insider perspectives on academic and workplace writing: Toward a continuum of rhetorical awareness. IEEE Transactions on Professional Communication, 51, 242-263.

Liang, X., \& Bilimoria, D. (2007). The representation and experience of women faculty in STEM fields. In R.J. Burke \& M.C. Mattis (Eds.), Women and minorities in science, technology, engineering and mathematics: Upping the numbers. (pp. 317-333). Northampton, MA: Elgar.

Longo, B. (2000). Spurious coin: A history of science, management, and technical writing. Albany: State University of New York Press.

Mallette, J. C. (2015). Engineer as writer and woman: Gender, identity, and professional discourse. (Unpublished doctoral dissertation). University of Arkansas, Fayetteville, AR.

Malone, E. A. (2010). Chrysler's “most beautiful engineer”: Lucille J. Pieti in the pillory of fame. Technical Communication Quarterly, 19, 144-183.

Malone, E. A. (2011). The first wave (1953-1961) of the professionalization movement in technical communication. Technical Communication, 58, 285-306.

Metz, S. S. (2007). Attracting the engineers of 2020 today. In R.J. Burke \& M.C. Mattis (Eds.), Women and minorities in science, technology, engineering and mathematics: Upping the numbers. (pp. 184-209). Northampton, MA: Elgar.

Miller, D. I., \& Wai, J. (2015). The bachelor's to Ph.D. STEM pipeline no longer leaks more women than men: A 30-year analysis. Frontiers in Psychology, 6, 1-10.

Moss-Racusin, C. A., Dovido, J. F., Brescoll, V. L., Graham, M. J., \& Handelsman, J. (2012). Science faculty’s subtle gender biases favor male students. PNAS, 109, 16474-16479.

Petroski, H. (1992). To engineer is human: The role of failure in successful design. New York, NY: Vintage.

Rossiter, M. W. (1995). Women scientists in America: Before affirmative action 1940-1972. Baltimore, Johns Hopkins University Press.

Simon, H. A. (1969). The sciences of the artificial. Cambridge, MA: MIT Press.

Stewart, A. J., Malley, J. E., \& LaVaque-Manty, D. (Eds.) (2007). Transforming science and engineering: Advancing academic women. Ann Arbor: University of Michigan Press.

Tebeaux, E., \& Dragga, S. (2015). The essentials of technical communication (3rd ed). New York: Oxford University Press.

Winsor, D. A. (1996). Writing like an engineer. Mahwah, NJ: Lawrence Erlbaum.

Winsor, D. A. (2003). Writing power: Communication within an engineering center. Albany: State University of New York Press.

Wolfe, J. (2006). Meeting minutes as a rhetorical genre: Discrepancies between professional writing textbooks and workplace practice. IEEE Transactions on Professional Communication, 49, 354-364.

Wolfe, J., \& Alexander, K. P. (2005). The computer expert in mixed-gendered collaborative writing groups. Journal of Business and Technical Communication, 19, 135-170.

Wolfe, J., \& Powell, E. (2009). Biases in interpersonal communication: How engineering students perceive gender typical speech acts in teamwork. Journal of Engineering Education, 98, 5-16.

Yates, J. K. (2001). Retention of nontraditional engineering construction professionals. Journal of Management in Engineering, 17, 41-48.

Yin, R. K. (2009). Case study research: Design and methods (4th ed.). Thousand Oaks, CA: Sage.

Yin, R. K. (2012). Applications of case study research (3rd ed.). Thousand Oaks, CA: Sage. 
This is an author-produced, peer-reviewed version of this article. The final, definitive version of this document can be found online at Journal of Business and Technical Communication, published by SAGE. Copyright restrictions may apply. doi: 10.1177/1050651917713253

\section{Author Biography}

Jennifer C. Mallette is an assistant professor at Boise State University, where she teaches in the Technical Communication Program. This article draws from her larger study examining the writing practices of women engineers and writing's connection to professional identity. 